\title{
Irrigation management: the optimization perspective
}

\author{
M. da Conceição Cunha \\ Department of Civil Engineering, Coimbra University, Portugal
}

\begin{abstract}
Irrigation management deals with many different decisions: the selection of economically viable cropping patterns, allocation of land per crop, allocation of water resources per crop, irrigation scheduling, management of irrigation deficit, etc. Plants need appropriate amounts of water, and its distribution during the full growing cycle has a tremendous influence on the final crop yield. This means that managing the soil water content is crucial to obtain an optimal allocation of water resources, supposing that the other production factors are adequate. The use of decision models to help irrigation management appears to be an interesting approach, as they are capable of handling different facets of such problems (economic, physiological, environmental, etc.) all together. This paper presents a synthetic state-of-the-art literature review of the optimization models for these purposes. The different agricultural production functions and their inclusion in the decision models are discussed.
\end{abstract}

Keywords: irrigation management, agricultural production functions, optimization models.

\section{Introduction}

Water is a scarce good in many regions of the world, and simultaneously it is the most important factor in some production processes, like agriculture. Supposing that the other production factors are at an adequate level, managing the soil water content is crucial to obtaining an optimal allocation of water resources. Irrigation supplements rainfall and can help to overcome the main risks associated with the uncertainty of hydrological events. In arid and semi-arid regions irrigation is intrinsically related to the availability of water resources, and thus deficit irrigation can occur. A benefit-cost analysis of irrigation systems should take 
into account the considerable investments (installation, operation and maintenance costs) needed to design and to operate a proper irrigation system, and the corresponding benefits in terms of crop yield improvement. Decision-aid models can be very helpful in finding the best decisions for irrigation management. In fact these models can incorporate the many of the different facets of such problems (economic, environmental, physiological, etc.).

This paper presents a synthetic state-of-the-art review of the optimization models found in the literature in this field. The different agricultural production functions are discussed, as well as their inclusion in the decision models.

\section{Irrigation management problems}

Many different situations can arise where irrigation management methodologies have to be used. As water is the principal factor in agricultural production, two cases can be considered: when the availability of water is adequate, and when it is not adequate. If there is enough water then irrigation can be timed to define the critical level. In this case the decision will be about the optimal allocation of the area to different crops in order to maximize the yield. Following the classification of Smout and Gorantiwar [32] we are dealing with area allocation models (Matanga and Marino [22], Maji and Heady [18], Afshar et al. [1], Onta et al. [24])

If water availability is inadequate, water deficits will occur. The way these deficits are distributed through the vegetative life cycle will have a tremendous influence on the final yield, consequently in benefits of the crop production. Therefore, in this kind of problem the best way to distribute the deficits has to be optimized. Two problems can be analysed here: ones where the cropping pattern is previously defined, and others where the cropping patterns are to be defined. The first situation gives rise to the water allocation models (Rao et al. [28], Hiessl and Plate [11], Paudyal and Manguerra [25], Vedula and Mujumbar [36], Wardlaw and Barnes [37], Kipkorir et al. [14]), and the second situation gives rise to the land and water allocation models (Matanga and Mariño [23], Kumar and Khepar [17], Yaron and Dinar [38], Rao et al. [27], Manocchi and Mecarelli [19], Sahoo et al. [30], Marques et al. [21], Smout and Gorantiwar [32], Gorantiwar and Smout [8]).

To solve any of the stated problems, information on the relations between crop yield and water applied is needed. These relations can be established for the entire growing season or for individual irrigation periods (when decisions are about intraseasonal allocation of water). Therefore it is important to establish agricultural production functions, incorporating the processes involved in crop development and the corresponding yield.

\section{Agricultural production functions}

The production of a given plant depends on many different factors, particularly on the amount of water available and its distribution during the vegetative life cycle. 
Two types of production functions are reported in the literature: seasonal crop-water production functions and dated crop-water production functions.

The first considers the effect of water availability in aggregated terms over the entire season. Equation (1) is an example of a production function of this type (Haxem and Heady [9]):

$$
Y_{k}-Y_{0 k}=\left(Y_{\max k}-Y_{0 k}\right) \exp \left[\frac{-\operatorname{coef}_{k}\left(X_{m k}-X_{k}\right)}{X_{k}}\right]
$$

$Y_{k}=$ seasonal relative yield for crop $k$ corresponding to $X_{k}$ depth of water applied; $Y_{0 k}=$ relative yield corresponding to zero irrigation allocation; $Y_{\operatorname{maxk}}=$ maximum relative yield obtainable for the initial soil and climatic conditions; $X_{m k}=$ minimum depth of water required to give potential relative yield $Y_{\operatorname{maxk}} ; \operatorname{coef}_{k}=$ coefficient for a particular crop.

Regarding dated crop-water production functions, it is important to point out that the final production depends on the allocation of the available water in the different periods of the life cycle. The final yield is sensitive to the period where there is a water deficit. Some periods in the vegetative life cycle are more critical than others, and the way this can influence the final yield is modelled using two approaches. A first approach that considers additive effects of the water deficits (Jensen [13]) and the second considers multiplicative effects.

The latter appears to be more realistic since it determines the development in each period, accounting for the conditions observed in the previous periods. An example of this type of model is given by Bowen and Young [2]:

$$
\frac{Y a}{Y m}=\prod_{i=1}^{N}\left(\frac{Y a_{i}}{Y m_{i}}\right)
$$

$Y_{a}=$ actual production; $Y_{m}=$ maximal production (when no factor limits production); $N$ : total number of periods; $i=$ period index, $Y_{a i}=$ actual production in period $i ; Y_{m i}=$ maximal production (when no factor limits production) in period $i$.

Another important aspect for the construction of the production functions is the way yield is related to water consumption. There are models that use a physiological approach, where the development results from a complex interaction between various physiological aspects (stomatic behaviour, photosynthesis, etc.), related to the amount of water available for irrigation. Usually they are not well systematized and are built for specific case studies. Hsiao et al. [12] emphasizes the difficulty of building a model of this type, when all the aspects contributing to plant development have to be considered. The most widespread models, like that devised by Doorenbos and Kassan [6], employ evapotranspiration for such purposes (here for dated production):

$$
\left(1-\frac{Y a_{i}}{Y m_{i}}\right)=K y_{i}\left(1-\frac{E T a_{i}}{E T m_{i}}\right)
$$


$K y_{i}=$ yield response coefficient in period $i ; E T a_{i}=$ actual evapotranspiration in period $i ; E T m_{i}=$ maximal evapotranspiration in period $i$ (if there is no irrigation deficit).

Evapotranspiration can also be used for the seasonal crop-water production function (Carvallo et al. [4]):

$$
Y_{a}=\left[A C+B C\left(\frac{E T a}{E T m}\right)^{\alpha}-C C\left(\frac{E T a}{E T m}\right)^{\beta}\right] Y_{m}
$$

AC, $B C, C C, \alpha, \beta=$ experimentally obtained coefficients.

To apply these models to real-world situations, the actual evapotranspiration should be expressed as a function of water availability in the soil. Soil moisture depletion is a complex process and the actual evapotranspiration depends on the moisture level between field capacity and the permanent wilting point. For operational purposes, theses processes are often simplified. Three examples taken from the literature will be described. The first one is proposed by Wardlaw and Barnes [37] and also used by Kumar et al. [16], and establishes that the ratio of actual evapotranspiration to maximal evapotranspiration is the same as the ratio of irrigation supply to irrigation demand:

$$
\frac{E T a}{E T m}=\frac{I}{D I}
$$

$I=$ irrigation supply; $D I=$ irrigation demand.

The second example, by Cunha et al. [5], proposed a model where the actual evapotranspiration is determined as a function of the soil water index $A S I_{i}$, that represents the fraction of the period where $E t a_{i}=E t m_{i}$ and depends on the water available in the soil:

$$
E T a_{i}=\left(c a_{i}+c b_{i} A S I_{i}\right) n d_{i}
$$

$c a_{i}, c b_{i}=$ coefficients of the linear regression model; $n d i=$ number of days of period $i$.

The hypotheses used to built this model imply that its validity is limited to the following situations:

$$
\begin{gathered}
0 \leq A S I_{i} \leq 1 \\
0.5 \operatorname{ETm}_{i} \leq E \operatorname{ETa}_{i} \leq \mathrm{ETm}_{i}
\end{gathered}
$$

The third one is given by Paul et al. [26]: 


$$
E T_{a}=\left\{\begin{array}{c}
0 ; S M=W P \\
\frac{\left.E T_{m}(S M-W P)\right)}{(1-p)(F C-W P)} ; W P \leq S M \leq(1-p)(F C-W P) \\
E T_{m} ; S M \geq(1-p)(F C-W P)
\end{array}\right\}
$$

$S M=$ soil moisture content; $W P=$ wilting point $F C=$ field capacity; $p=$ crop water depletion factor.

Quite recently Schmitz et al. [31] presented an innovative work for establishing water application parameters to create an optimal soil moisture profile using an artificial neural network approach.

The incorporation of the different agricultural production functions into decision processes will lead to decision-aid models that differ in terms of their mathematical characteristics.

\section{Decision-aid models}

In the last twenty years the literature has reported a number of decision-aid models to solve irrigation management problems. Linear programming, nonlinear programming and dynamic programming techniques and, quite recently, genetic algorithms are among the most popular methods employed to solve irrigation management problems. Irrigation management models can become more complex if the decisions are simultaneously about the hydraulic infrastructures needed for storage and / or to supply water (reservoirs, canals, wells in an aquifer, etc.). The inclusion of uncertainty issues is also challenging when it comes to solving large scale irrigation management problems.

Three different representative objective functions will be described. The first aims to optimize the water allocation among various crops (Kumar et al. [16])

$$
\operatorname{Max} \sum_{c=1}^{N C}\left\{1-\sum_{g=1}^{N G S} K y_{g}^{c}\left(1-\frac{\sum_{i \in g} E T a_{t}^{c}}{\sum_{i \in g} E \operatorname{Tm}_{t}^{c}}\right)_{g}\right\}
$$

$N C=$ number of crops; $c=$ crop index; $N G S=$ number of growth stages; $K y_{g}^{c}=$ yield response coefficient for the growth stage $g$ of the crop $c ; \mathrm{ETa}^{\mathrm{c}}=$ actual evapotranspiration for period $t$ for $\operatorname{crop} c$; and $E \operatorname{Tm}^{c}=$ maximal evapotranspiration for period $t$ for crop $c$.

This objective function was used for water allocation when determining the operating policy for an irrigation reservoir. Constraints on reservoir water balance were considered. The decision-model was solved by a genetic algorithm. 
The second objective function was built for the optimal allocation of irrigation water supplies in real time (Wardlaw and Barnes [37]):

$$
\operatorname{Min} \sum_{s=1}^{N S C} \frac{1}{Y m_{s}}\left(Y m_{s}-Y a_{s}\right)^{2}
$$

$N S C=$ number of different irrigation schemes; $s=$ irrigation scheme index

This model was considered for the management of a run-of-river with a complex distribution network. Non-linear programming (quadratic programming) was the method chosen to solve the decision model.

Another nonlinear objective function is presented in Carvallo et al. [4] for maximizing the profit of irrigation under water availability constraints:

$$
\operatorname{Max} \sum_{l=1}^{N S} \sum_{c=1}^{N C}\left(P_{j} A_{l j} Y a_{l j}-C_{l j} A_{l j}\right)
$$

$N S=$ number of soil types; $l=$ soil type index; $N C=$ number of crops; $P=$ price received for crop $j ; A_{l j}=$ area cultivated of soil $l$ and $\operatorname{crop} c ; C_{l j}=$ production cost per unit are of soil $l$ and $\operatorname{crop} c$.

The decision-aid model includes soil, water and labour availability constraints, as well as crop rotation and market limitations on the area to be cultivated for each crop.

Cunha et al. [5] presented a nonlinear objective function for maximizing the net benefits of an irrigated area of a given crop, with the water supplied by an aquifer:

$$
\operatorname{Max} P_{y} Y_{\max } \prod_{i=1}^{N} \frac{Y_{a_{i}}}{Y_{\max _{i}}}-\sum_{i=1}^{N} C_{e k} \sum_{k=1}^{M}\left(H S_{k}+R_{k, i}\right) Q_{k, i}
$$

$N=$ number of periods; $P_{y}=$ price received for the crop; $C_{e k}=$ energy cost per unit of flow and elevation head in well $k ; M=$ number of wells; $H S_{k}=$ static level in the well $k ; R_{k, i}=$ drawdown in well $k$, as a function of pumping in the well $k$ and in all other wells until period $i$; $Q_{k, i}$ flow pumped in well $k$ in period $i$.

The decision model incorporates a groundwater flow model for drawdown calculations as a consequence of the flows pumped for irrigation purposes.

Linear decision models (Tintner [34]) are very limited in terms of representing real world problems (Hazell and Norton [10]). But the software and hardware capabilities available have, for some years, made it difficult to use more sophisticated approaches.

Dynamic programming models have been widely used in the context of irrigation management (Dudley et al. [7], Matanga and Mariño [23], Knapp et al. [15]). Even with relatively small case studies, dimensional problems can arise and an intractable computational situation can result. Combining linear 
programming and dynamic programming could help to avoid some of these limitations (Yaron and Dinar [38], Vedula and Nagesh Kumar [35]). Recently, Mannocchi and Todisco [20] built a three-step model for the optimal weekly intraseasonal operation of a multipurpose reservoir. A parametric dynamic programming model was used to avoid the "curse of dimensionality". Paul et al. [26] have developed a multilevel approach for determining optimal seasonal water allocation and optimal cropping pattern, based on coupling deterministic dynamic programming and stochastic dynamic programming.

Stochastic aspects characterizing the evapotranspiration demands (or the variable linked to the evapotranspiration representing the crop water requirements) were included in the dynamic programming models for single crop situation by Rhenals and Bras [29], and Bras and Cordova [3]. Multicrop situations were dealt with by Sunantara and Ramirez [33] in an optimal seasonal irrigation water allocation and an optimal stochastic intraseasonal (daily) irrigation scheduling model, by Vedula and Nagesh Kumar [35] in the context of a single purpose irrigation reservoir, and by Rao et al. [28] that used heuristically derived seasonal crop-water production functions. Marques et al. [21] have described a two-stage stochastic quadratic programming technique for taking decisions on perennial and annual crops, water use, irrigation technologies and economic performance.

\section{Conclusions}

A synthetic review of irrigation management models has been presented. Many diverse issues can be incorporated into these models, giving more or less complex models. Considering water the principal factor in agricultural production, the relation between crop yield and the corresponding water requirements is analysed. New developments in mathematical programming and in hardware capabilities are allowing large size problems to be tackled, more closely representing real world irrigation management problems.

\section{Acknowledgment}

The author gratefully acknowledges support received from the Fundação para a Ciência e a Tecnologia through grant POCI/AGR/59180/2004.

\section{References}

[1] Afshar, A., Marino, M. A., and Abrishamchi, A. (1991), "Reservoir planning for irrigation district.” J. Water Resour. Plan. Manage., 117(1), pp. 74-85.

[2] Bowen, R.L., Young, R.A. (1985), "Financial and economic irrigation net benefits functions for Egypt's Northern delta", Water Resources Research, 21, pp. 1329-1335. 
[3] Bras, R. L., and Cordova, J. R. (1981), "'Intra-seasonal water allocation in deficit irrigation.” Water Resour. Res., 17(4), pp.866-874.

[4] Carvallo, H.O., Holzapfel, E.A., Lopez, M.A., Mariño (1998), “Irrigated cropping optimization “.J. Irrig. Drain. Eng., 124(2), pp. 67-72.

[5] Cunha, M. C. M. O., Hubert, P., Tyteca, D. (1993), "Optimal management of a groundwater system for seasonally varying agricultural production". Water Resources Research, 29(7), pp. 2415-2425.

[6] Doorenbos, J., Kassam, A.H. (1979), "Yield response to water", FAO Irrigation and Drainage Paper, 33, Food and Agric. Org., Roma, Itália.

[7] Dudley, N.J., Howell, D.T., Musgrave, W.F. (1971), "Irrigation planning 2: Choosing optimal acreages within a season”, Water Resour. Res., 7(5), pp. 1051-1063.

[8] Gorantiwar, S.D, Smout, I.K. (2005), "Multilevel approach for optimizing land and water resources and irrigation deliveries for tertiary units in large irrigation schemes. I: Application”, J. Irrig. Drain. Eng. 131(3), pp. 264 272.

[9] Haxem, R. W., and Heady, E. O. (1978), Water production function for irrigated agriculture. Iowa State University Press, Ames, Iowa.

[10] Hazell, P.B.R., Norton, R.D. (1997), Mathematical Programming for Economic Analysis in Agriculture, Macmillan, New York.

[11] Hiessl, H., and Plate, E. J. (1990), "A heuristic closed-loop controller for water distribution in complex irrigation systems." Water Resour. Res. 26(7), pp. 1323-1333.

[12] Hsiao, T.C., Fereres, E., Acevedo, E., Henderson, D.W. (1976), "Waterstress and dynamics of growth and yield of crop plants", Ecol. Studies, 19, pp. 281-305.

[13] Jensen, M.E. (1968), "Water consumption by agricultural plants", Water Deficit and Plant Growth, Vol 2, Ed by T.T. Koslowski, pp. 1-22, Academic, San Diego, California.

[14] Kipkorir, E. C., Raes, D., and Labadie, J. L. (2001), “Optimal allocation of short-term irrigation supply.” Irrig. Drain. Syst., 15, 247-267.

[15] Knapp, K., Stevens, B.K., Letey, J.L., Oster, J.D. (1990), “A dynamic optimization model for irrigation investment and management under limited drainage conditions", Water Resour. Res. 26(7), pp. 1335-1343.

[16] Kumar, D.N., Raju, K.S., Ashok, B. (2006), “Optimal Reservoir operation for irrigation of multiple crops using genetic algorithms", J. Irrig. Drain. Eng., 132(2), pp. 123-129.

[17] Kumar, R., and Khepar, S. D. (1980), "Decision models for optimal cropping patterns in irrigations based on crop water production functions." Agric. Water Manage. 3, pp. 65-76.

[18] Maji, C. C., and Heady, E. O. (1978), "Intertemporal allocation of irrigation water in the Mayurakshi Project (India): An application of chance-constrained linear programming." Water Resour. Res., 14(2), pp. 190-196.

[19] Mannocchi, F., and Mecarelli, P. (1994), “Optimization analysis of deficit irrigation systems.” J. Irrig. Drain. Eng., 120(3), pp. 484-503. 
[20] Mannocchi, F., Todisco, F. (2006), "Optimal reservoir operations for irrigation using a three spatial scales approach”, J. Irrig. Drain.Eng., 132(2), pp. 130-206.

[21] Marques, F.M., Lund, J.R., Howitt, R.E. (2005), "Modelling irrigated agricultural production and water use decisions under water supply uncertainty", Water Resour. Res., 41(3), W08423.

[22] Matanga, G. B., and Marino, M. A. (1977), "Application of optimization and simulation techniques to irrigation management." Water Science and Engineering, Paper No. 5003, Department of Land, Air and Water Resources, Univ. of California, Davis, Calif.

[23] Matanga, G. B., and Marino, M. A. (1979), "Irrigation planning: 1. Cropping pattern." Water Resour. Res., 15(3), pp. 672-678.

[24] Onta, P. R., Loof, R., and Banskota, M. (1995), "Performance-based irrigation planning under water shortage.” Irrig. Drain. Syst. 9, pp. 143162.

[25] Paudyal, G. N., and Manguerra, H. B. (1990), "Two-step dynamic programming approach for optimal irrigation water allocation." Water Resour. Manage. 4, pp.187-204.

[26] Paul, S., Panda, S. N., and Nagesh Kumar, D. (2000), “Optimal irrigation allocation: A multilevel approach.” J. Irrig. Drain. Eng. 126(3), pp. 149156.

[27] Rao, K. S. V. V. S., Reddi, T. B., Rao, M. V. J., and Reddi, G. H. S. (1986), "A rational approach for crop planning in the command areas of irrigation projects.” J. Inst. Eng. (India) Agric. Eng. Div. 66(1), pp.70-75.

[28] Rao, N. H., Sarma P. B. S., and Chander, S. (1990), "Optimal multicrop allocation of seasonal and intraseasonal irrigation water." Water Resour. Res. 26(4), pp. 551-559.

[29] Rhenals, A. E., and Bas, R. L. (1981), "The irrigation scheduling problem and evapotranspiration uncertainty." Water Resour. Res., 17(5), pp. 13281338 .

[30] Sahoo, G. B., Loof, R., Abernethy, C. L., and Kazama, S. (2001), "Reservoir release policy for large irrigation system.” J. Irrig. Drain. Eng. 127(5), pp. 302-310.

[31] Schmitz, G.H., Schutze, N., Petersohn, U. (2002), “New strategy for optimizing water application under trickle irrigation“, J. Irrig. Drain. Eng. 128(5), pp. 287-297.

[32] Smout, I.K., Gorantiwar, S.D. (2005), "Multilevel approach for optimizing land and water resources and irrigation deliveries for tertiary units in large irrigation schemes. I: Method", J. Irrig. Drain. Eng. 131(3), pp. 254-263.

[33] Sunantara, J. D., and Ramirez, J. A. (1997), “Optimal stochastic multicrop seasonal and intraseasonal irrigation control." J. Water Resour. Plan. Manage. 123(1), pp. 39-48.

[34] Tintner, G. (1955), "Stochastic linear programming with application to agricultural economics", in Second Symposium in Linear Programming, 
246 Sustainable Irrigation Management, Technologies and Policies

Ed by H.A. Antosiewicz, pp. 197-229. Natl. Bur. Stand., Washington, D.C.

[35] Vedula, S., and Nagesh Kumar, D. (1996), “An integrated model for optimal reservoir operation for irrigation of multiple crops." Water Resourc. Res., 32(4), 1101-1108.

[36] Vedula S., and Mujumdar, P. P. (1992), “Optimal reservoir operation for irrigation of multiple crops." Water Resour. Res. 28(1), pp. 1-9.

[37] Wardlaw, R., and Barnes, J. (1999), “Optimal allocation of irrigation water supplies in real time.” J. Irrig. Drain. Eng. 125(6), pp. 345-354.

[38] Yaron, D., and Dinar, A. (1982), "Optimum allocation of farm irrigation water during peak seasons.” Am. J. Agric. Econom., 64, pp. 681-689. 